\title{
Rainfall Variability under Present and Future Climate Scenarios Using the Rossby Center Bias-Corrected Regional Climate Model
}

\author{
Jane Wangui Mugo ${ }^{1,2^{*}}\left(\mathbb{D}\right.$, Franklin J. Opijah ${ }^{2}$, Joshua Ngaina1,2, Faith Karanja3 ${ }^{3}$, Mary Mburu ${ }^{4}$ \\ ${ }^{1}$ Department of Meteorology, South Eastern Kenya University, Kwa Vonza, Kenya \\ ${ }^{2}$ Department of Meteorology, University of Nairobi, Nairobi, Kenya \\ ${ }^{3}$ Department of Geospatial and Space Technology, University of Nairobi, Nairobi, Kenya \\ ${ }^{4}$ Department of Agriculture and Veterinary Sciences, South Eastern Kenya University, Kwa Vonza, Kenya \\ Email: ^jmugo@seku.ac.ke, ^jannymugo@gmail.com
}

How to cite this paper: Mugo, J. W., Opijah, F. J., Ngaina, J., Karanja, F., \& Mburu, M. (2020). Rainfall Variability under Present and Future Climate Scenarios Using the Rossby Center Bias-Corrected Regional Climate Model. American Journal of Climate Change, 9, 243-265.

https://doi.org/10.4236/ajcc.2020.93016

Received: June 3, 2020

Accepted: September 5, 2020

Published: September 8, 2020

Copyright $\odot 2020$ by author(s) and Scientific Research Publishing Inc. This work is licensed under the Creative Commons Attribution International License (CC BY 4.0).

http://creativecommons.org/licenses/by/4.0/

\begin{abstract}
This study sought to determine the spatial and temporal variability of rainfall under past and future climate scenarios. The data used comprised stationbased monthly gridded rainfall data sourced from the Climate Research Unit (CRU) and monthly model outputs from the Fourth Edition of the Rossby Centre (RCA4) Regional Climate Model (RCM), which has scaled-down nine GCMs for Africa. Although the 9 Global Climate Models (GCMs) downscaled by the RCA4 model was not very good at simulating rainfall in Kenya, the ensemble of the 9 models performed better and could be used for further studies. The ensemble of the models was thus bias-corrected using the scaling method to reduce the error; lower values of bias and Normalized Root Mean Square Error (NRMSE) were recorded when compared to the uncorrected models. The bias-corrected ensemble was used to study the spatial and temporal behaviour of rainfall under baseline (1971 to 2000) and future RCP 4.5 and 8.5 scenarios (2021 to 2050). An insignificant trend was noted under the baseline condition during the March-May (MAM) and October-December (OND) rainfall seasons. A positive significant trend at 5\% level was noted under RCP 4.5 and 8.5 scenarios in some stations during both MAM and OND seasons. The increase in rainfall was attributed to global warming due to increased anthropogenic emissions of greenhouse gases. Results on the spatial variability of rainfall indicate the spatial extent of rainfall will increase under both RCP 4.5 and RCP 8.5 scenario when compared to the baseline; the increase is higher under the RCP 8.5 scenario. Overall rainfall was found to be highly variable in space and time, there is a need to invest in the early dissemination of weather forecasts to help farmers adequately prepare in case of unfavorable weather. Concerning the expected increase in rainfall in the fu-
\end{abstract}


ture, policymakers need to consider the results of this study while preparing mitigation strategies against the effects of changing rainfall patterns.

\section{Keywords}

CORDEX, Climate Change, Bias Correction, Ensemble, Rainfall, Kenya, RCA4

\section{Introduction}

Natural resources drive economic growth and livelihoods in Kenya. This dependence means that fluctuation in climate, especially in rainfall; undesirably affects the biological, physical, and socio-economical setups resulting in disasters such as loss of livestock and crop failure in the agricultural sector (Bobadoye et al., 2014; Omoyo et al., 2015). Agriculture is likely to be the most vulnerable sector to the changing climate with stress on subsistence farming in the tropical region, as smallholder farmers lack sufficient resources to acclimatize to climate change (Eriksen et al., 2005; Adhikari et al., 2015). Understanding the spatial variability of climate parameters can help fight hunger and poverty and improve the wellbeing of smallholder farmers by improving their management of natural resources for agricultural production (Mugo et al., 2016).

Rainfall in its spatial and temporal variability is one of the major drivers determining agricultural productivity in a region and in turn food security (Omoyo et al., 2015; Ochieng et al., 2016). Since farmers are highly dependent on rain-fed agriculture policy makers need to understand how rainfall will behave in the future to develop long-term agricultural policies (Holzkämper et al., 2011; El-Beltagy \& Madkour, 2012). The spatial variability of rainfall over Kenya has been conducted by many researchers, showing that it exhibits high spatial and temporal variability (Indeje et al., 2001; Ongoma et al., 2015; Ongoma \& Chen, 2017). There is general agreement that climate is changing making rainfall unpredictable and increasing the frequency of extreme weather events (Thornton et al., 2008).

Global climate models and regional climate models are examples of datasets used during climate impact studies. These models often carry biases which if unattended can spill over into climate change adaptation strategies (Ayugi et al., 2020). In Kenya some studies show the main rainfall season March-May (MAM) is no longer as reliable as the October-December (OND) season (Shisanya et al., 2011; Ayugi et al., 2016; Ongoma \& Chen, 2017; Yang et al., 2017; Ouma et al., 2018); however, GCMs predictions over the region show wetter conditions inconsistent with observed trends especially for the MAM season.

A common step towards reducing uncertainties in global models is to use a multi-model ensemble (MME) of several GCMs which despite often performing better than individual models still carry errors (Endris et al., 2013; Ogega et al., 2016; Mukhala et al., 2017; Mutayoba \& Kashaigili, 2017). Bias correcting rainfall 
before using it for future studies is important as demonstrated by other studies (Terink et al., 2010; Ezéchiel et al., 2016; Ayugi et al., 2020; Liu et al., 2020; Vigna et al., 2020; Worku et al., 2020). This study used a MME of nine GCMs (downscaled using the CORDEX Fourth edition of Rossby Centre (RCA4) Regional Climate Model (RCM)) bias-corrected using the scaling method to study the spatial and temporal variability of rainfall under past and future climates (RCP 4.5 and RCP 8.5 scenarios). The RCA4 RCM was chosen since it has downscaled the largest number of GCMs for Africa under the CORDEX project, and there is a need to study how well these downscaled GCMs compare with observed data.

\section{Materials and Methods}

\subsection{Study Area}

Kenya (Figure 1) lies between latitudes $5^{\circ} \mathrm{N}$ and $5^{\circ} \mathrm{S}$ and longitudes $34^{\circ} \mathrm{E}$ and $42^{\circ} \mathrm{E}$ with a land area of approximately $584,000 \mathrm{~km}^{2}$. Kenya is characterised by large water bodies and a varying topography which gives rise to a range of climatic

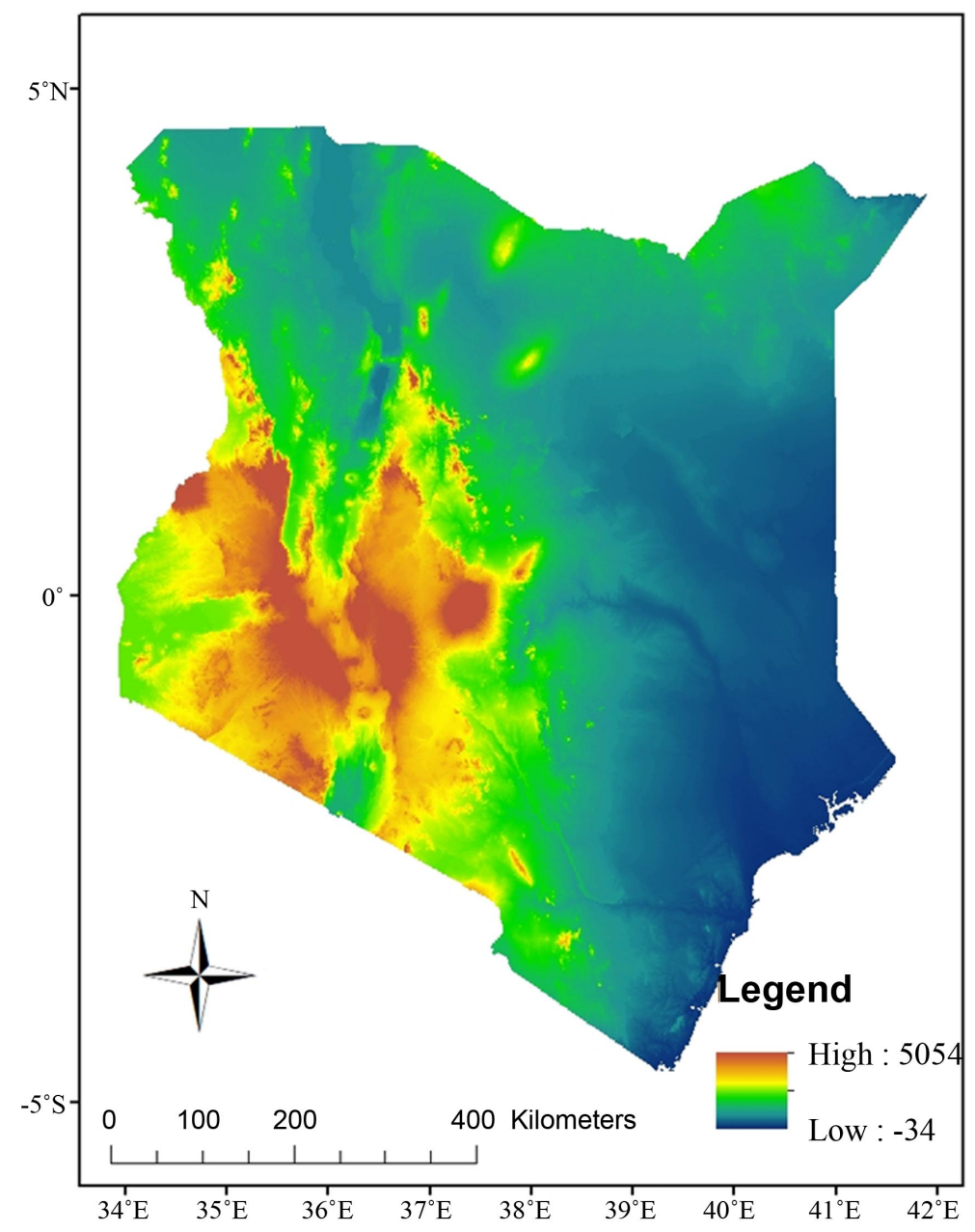

Figure 1. Topography of the study area (in meters). The brown regions show areas of high elevation decreasing through to the blue regions. 
conditions. Climatic patterns in Kenya are influenced by the presence of high mountains such as Mount Kenya and Mount Kilimanjaro, the Indian Ocean, Lake Tanganyika, and Lake Victoria.

Kenya receives rainfall in a bimodal pattern mainly controlled by the movement of the ITCZ as it migrates north and south. The long rains start around March to June, peaking around March to May; the short rains start from September and drain away in November or December (Okoola, 1999; Herrero et al., 2010). The Madden Julian oscillation causes decreased rainfall in the OND season over the East Africa region and increased rainfall during MAM (Omeny et al., 2008). Indeje et al., (2000) found there was a strong significant correlation between the equatorial stratospheric lower zonal wind and rainfall over some parts of East Africa. Kenya's rainfall is also dependent on monsoon circulation; it experiences the Northeast monsoon which drives dry air into Kenya during the DJF season and Southeast monsoon which bring cool moist air from June to August (JJA) season (Okoola, 1999).

The amount of rainfall received is correlated to topography; for example, the highest elevation regions receive up to $2300 \mathrm{~mm}$ per year whilst the low plateau receives only $320 \mathrm{~mm}$. Over two-thirds of the country receives less than $500 \mathrm{~mm}$ of rainfall per year, particularly areas around the northern parts of the country (Herrero et al., 2010). Rainfall in Kenya has high variability across different regions, with the Arid and Semi-Arid Lands (ASALS) experiencing the highest variability in time and space.

\subsection{Data Description}

This study used monthly gauge-based station data from the Kenya Meteorological Service for the homogeneous climate zones and station-based monthly gridded rainfall data sourced from the Climate Research Unit (CRU) at $0.5^{\circ}$ by $0.5^{\circ}$ grid resolution (Harris et al., 2014); both datasets spanned from 1971 to 2000. The CRU dataset has been validated against observed data in Kenya and found useful (Ongoma \& Chen, 2017). The third dataset comprised monthly gridded data sourced from the Fourth Edition of the Rossby Centre (RCA4) Regional Climate Model (RCM), which has scaled down nine GCMs in Africa at a $0.44^{\circ}$ by $0.44^{\circ}$ grid resolution (Table 1 ). Since the data from CRU and RCA4 had different resolutions, the model outputs were converted to a $0.5^{\circ}$ by $0.5^{\circ}$ grid using bilinear interpolation to reduce the effects of resolution in the comparison.

The observed datasets from 1971 to 2000 were used to assess the ability of the downscaled RCA4 models to simulate rainfall in Kenya for the same period. The best performing model was adjusted for errors using the scaling method and then used to project changes in rainfall over the study area for the RCP 4.5 and RCP 8.5 scenarios from 2021 to 2050 which is the implementation period of Kenya's vision 2030 goals. The RCP 4.5 scenario assumes that everything goes on as usual (Clarke et al., 2009; Wise et al., 2009), while the RCP 8.5 scenario represents the worst-case scenario (Riahi et al., 2011). 
Table 1. Global climate models downscaled by the RCA4 model under the CORDEX africa project (Endris et al., 2013).

\begin{tabular}{llcc}
\hline & \multicolumn{1}{c}{ Institute Name } & GCM Name & Calendar Days \\
\hline 1 & Canadian Center for Climate Modelling and Analysis (CCCma) & CanESM2 & 365 days \\
2 & Centre National de Recherches Météorologiques (CNRM-CERFACS) & CNRM-CM5 & Standard \\
3 & Met Office Hadley Centre (MOHC) & HadGEM2-ES & 360 days \\
4 & Norwegian Climate Centre (NCC) & NorESM1-M & 365 days \\
5 & Commonwealth Scientific and Industrial Research Organisation (CSIRO) & QCCCE-CSIRO-Mk3-6-0 & 365 days \\
6 & Model for Interdisciplinary Research on Climate (MIROC) & MIROC5 & 365 days \\
7 & National Oceanic and Atmospheric Administration-Geophysical Fluid Dynamics & GFDL-ESM2M & 365 days \\
8 & Laboratory (NOAA-GFDL) & Max Planck Institute for Meteorology (MPI-M) & CM5A-MR \\
9 & Institut Pierre Simon Laplace (IPSL) & Standard & 365 days \\
\hline
\end{tabular}

\subsection{Methodology}

\subsubsection{Trend Analysis}

The Mann-Kendall test statistic used to determine trend $(S)$ was computed using Equation (1) (Mann, 1945; Kendall, 1975), where $x_{j}$ represents the successive values and $n$ represents the number of data points in a set.

$$
\begin{gathered}
S=\sum_{i=1}^{n-1} \sum_{j=1+1}^{n} \operatorname{sgn}\left(x_{j}-x_{i}\right) \\
\operatorname{sgn}\left(x_{j}-x_{i}\right)= \begin{cases}+1 & \text { if }\left(x_{j}-x_{i}\right)>0 \\
0 & \text { if }\left(x_{j}-x_{i}\right)=0 \\
-1 & \text { if }\left(x_{j}-x_{i}\right)<0\end{cases}
\end{gathered}
$$

Accordingly, $S$ increases (or decreases) by 1 if the current variable is larger (or smaller) than the previous variable (Equation (2)). The variance statistic, $\operatorname{Var}(S)$, is given by Equation (3) where $r$ and $t_{p}$ represent, respectively, the number of tied clusters and data points in the $p^{\text {th }}$ tied group. $S$ and $\operatorname{Var}(S)$ values are used to calculate the test $Z$ value as shown in Equation (4):

$$
\begin{gathered}
\operatorname{Var}(S)=\frac{n(n-1)(2 n+5)-\sum_{p=1}^{r} t_{p}\left(t_{p}-1\right)\left(2 t_{p}+5\right)}{18} \\
Z= \begin{cases}\frac{S-1}{\sqrt{\operatorname{Var}(S)}} & \text { if } S>0 \\
0 & \text { if } S=0 \\
\frac{S+1}{\sqrt{\operatorname{Var}(S)}} & \text { if } S<0\end{cases}
\end{gathered}
$$

If the calculated value is larger than the significance level, an increasing (decreasing) trend is reported if the variable $Z$ is positive (negative). The trend is insignificant if the calculated value of $Z$ is smaller than the level of significance. A significance level of $5 \%$ was applied.

The magnitude of the trend was predicted using the Sen's estimator, $Q_{i}$ (Sen, 
1968). The slope $\left(T_{i}\right)$ of all pairs of data is calculated using (Equation (5)), in which the parameters $x_{j}$ and $x_{k}$ are the values of data at period $j$ and $k$, where $j$ is greater than $k$. The mean of the $n$ values of $T_{i}$ is symbolized as the Sen's estimator of slope and computed using Equation (6).

$$
T_{i}=\frac{x_{j}-x_{k}}{j-k}
$$

For $i=1,2, \cdots, n$

$$
Q_{i}= \begin{cases}\frac{T_{n+1}}{2} & \text { if } n \text { is odd } \\ \frac{1}{2}\left(T_{\frac{n}{2}}+T_{\frac{n+2}{2}}\right) & \text { if } n \text { is even }\end{cases}
$$

Positive and negative values of $Q_{i}$ indicate, respectively, a trend that is increasing and decreasing in the time series. The percentage change $(\% \Delta)$ of the Sen's slope over mean rainfall per unit time was computed using (Equation (7)) (Duhan \& Pandey, 2013; Taxak et al., 2014).

$$
\% \Delta=\frac{n Q_{i} * 100}{\bar{x}}
$$

\subsubsection{Performance of Models in Simulating Historical Climate}

The performance of the RCA4 model in simulating the historical climate was assessed using various error analysis measures. The outputs from the RCA4 model were evaluated against the observed data using the correlation coefficient (Equation (8)), bias (Equation (9)), and the normalised root mean square error (NRMSE) (Equation (11)) statistical measures (Luhunga et al., 2016; Mutayoba \& Kashaigili, 2017).

$$
\begin{gathered}
R=\frac{\sum_{i=1}^{N}\left(O_{i}-\bar{O}\right) \cdot\left(P_{i}-\bar{P}\right)}{\sqrt{\sum_{i=1}^{N}\left(O_{i}-\bar{O}\right)^{2} \cdot \sum_{i=1}^{N}\left(P_{i}-\bar{P}\right)^{2}}} \\
\text { Bias }=\frac{1}{N} \sum_{i=1}^{N}\left(P_{i}-O_{i}\right) \\
\text { NRMSE }=\frac{\operatorname{RMSE}}{\bar{O}} \times 100 \\
\text { RMSE }=\sqrt{\frac{1}{N} \sum_{i=1}^{N}\left(P_{i}-O_{i}\right)^{2}}
\end{gathered}
$$

where $O_{i}, \bar{O}, P_{i}, \bar{P}$ and $N$ are the values of observed, mean of observed, predicted, and mean of predicted and the total number of these pairs respectively.

Bias correction was done using the scaling, or the change factor, method due to its wide usage in literature (Wetterhall et al., 2012; Ezéchiel et al., 2016; Akhter et al., 2017) which is given by Equation (12), where $P_{C, i}$ and $P_{O, i}$ are the corrected and uncorrected model outputs respectively; $\Delta_{p}$ and $\Delta_{r}$ is the average observed and GCM precipitation during the reference period.

$$
P_{C, i}=P_{O, i} \times \frac{\Delta_{p}}{\Delta_{r}}
$$




\section{Results and Discussions}

The results are presented and discussed on the spatial and temporal trends in rainfall under the baseline and future conditions using a bias-corrected ensemble of nine GCMs downscaled by the RCA4 model. An assessment of the performance of the individual models and the ensemble in simulating observed rainfall is first conducted before bias correction.

\subsection{Assessment of the Performance of Climate Models in Simulating the Annual Cycle of Rainfall}

Figure 2 shows the annual pattern of rainfall in four regions in Kenya i.e. North West (Lodwar), western (Kakamega), southeastern (Garissa), and coastal (Voi) regions. Kenya experiences two rainfall peaks that occur during MAM and OND seasons in most regions, with the movement of the ITCZ. Some areas in the Western part of the country (e.g. Lodwar and Kakamega) receive rainfall during the JJA season due to the advection of cool moist air from the southeast monsoon.

The models capture the bimodal pattern of annual rainfall following the movement of the ITCZ but fail to simulate the JJA season observed at Lodwar and Kakamega. Most of the models underestimate rainfall during the MAM season and overestimate rainfall in the OND season. The tendency of the CMPI models to underestimate MAM rainfall and overestimate rainfall in OND over East Africa has also been reported by other authors (Yang et al., 2015; Ongoma et al., 2019).
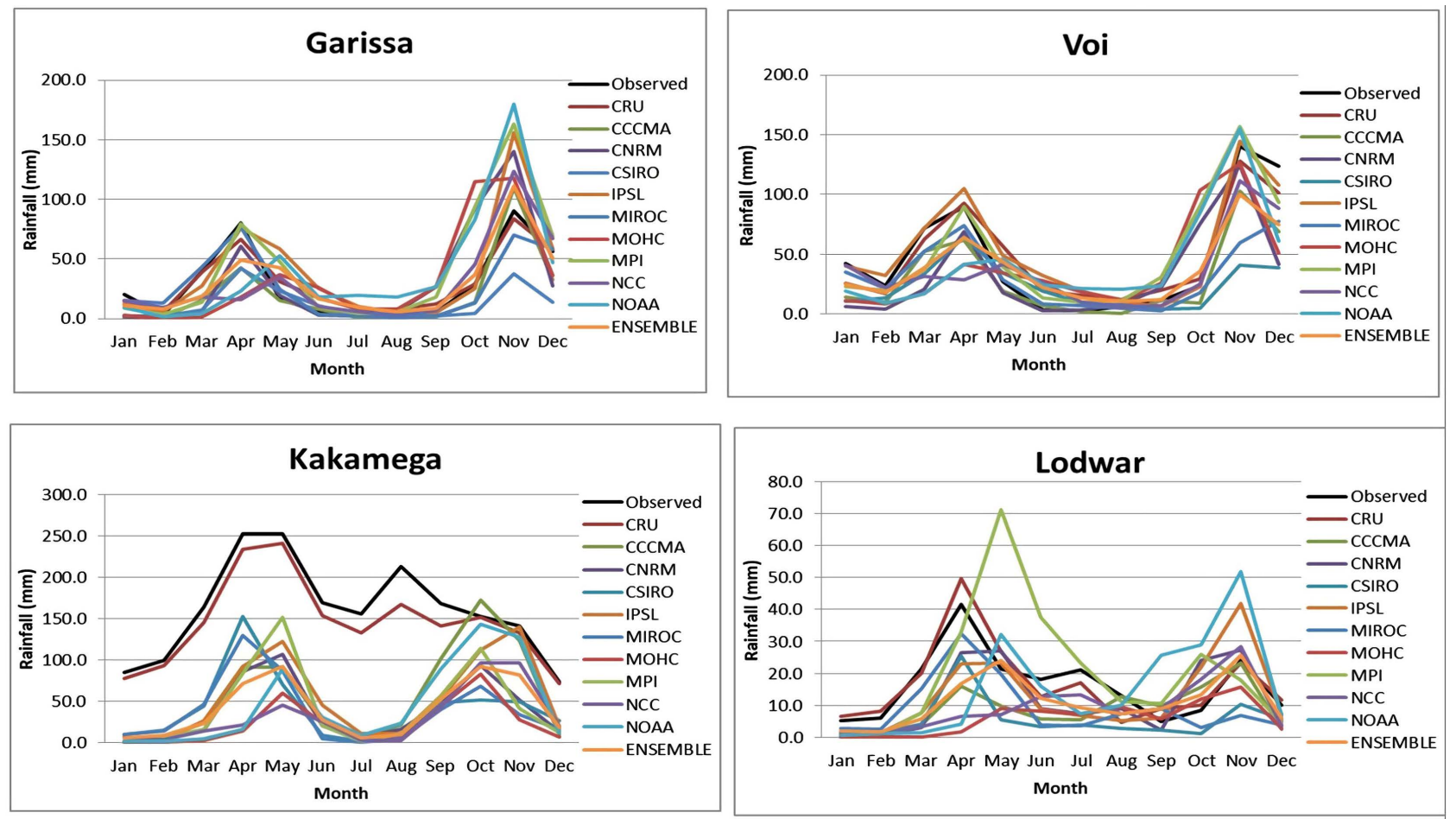

Figure 2. Average monthly rainfall (mm) patterns for sample stations in Kenya during the 1971 to 2000 period. 


\subsection{Performance of Climate Models in Simulating the Spatial Distribution of MAM and OND Rainfall}

This subsection presents the performance of the RCA4 model in simulating the spatial distribution of rainfall during the MAM and OND seasons which are the main rainfall seasons in Kenya.

\subsubsection{Climatology of Observed and Simulated Rainfall}

Figure 3 and Figure 4 are the spatial plots of rainfall climatology for the CRU and RCA4 model outputs during the MAM and OND seasons respectively. Rainfall is concentrated in the western, central, and coastal parts of Kenya. The rainfall pattern could be attributed to the influence of the mesoscale systems around the regions and the apparent position of the ITCZ which is around the equator. All the nine models and their ensemble overestimate rainfall over the central and western part of the county which are high altitude regions. Models tend to have poor accuracy in high altitude areas and bias correction is often recommended before further studies (Endris et al., 2013; Mukhala et al., 2017; Kisembe et al., 2019). The models however have better skill in the low altitude areas indicating models tend to perform better as altitude decreases.
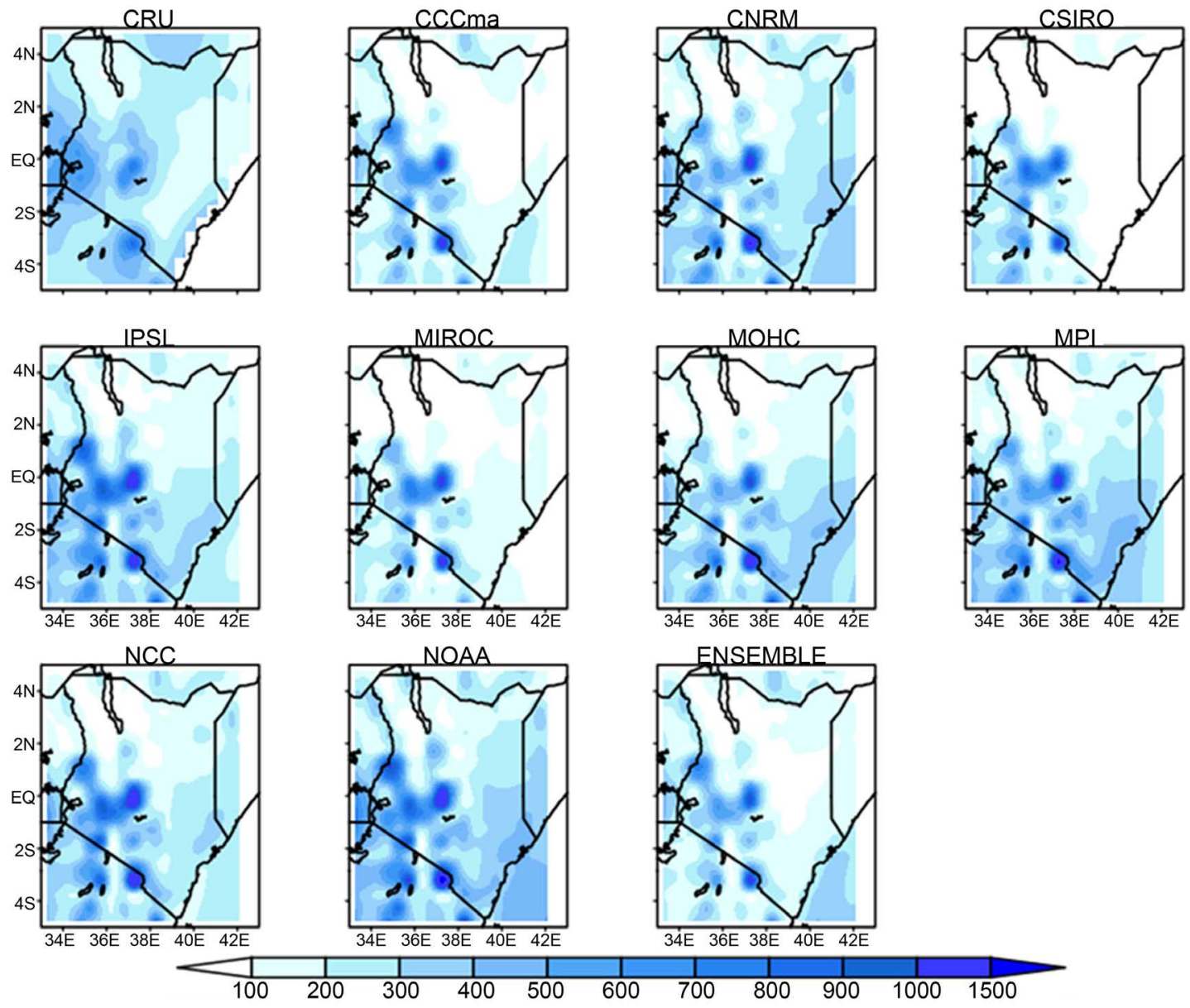

Figure 3. Performance of RCA4 model in simulating the observed MAM rainfall total (in mm) over Kenya for 1971-2000. Rainfall amount increases from the white shaded areas through to the red shaded areas. 

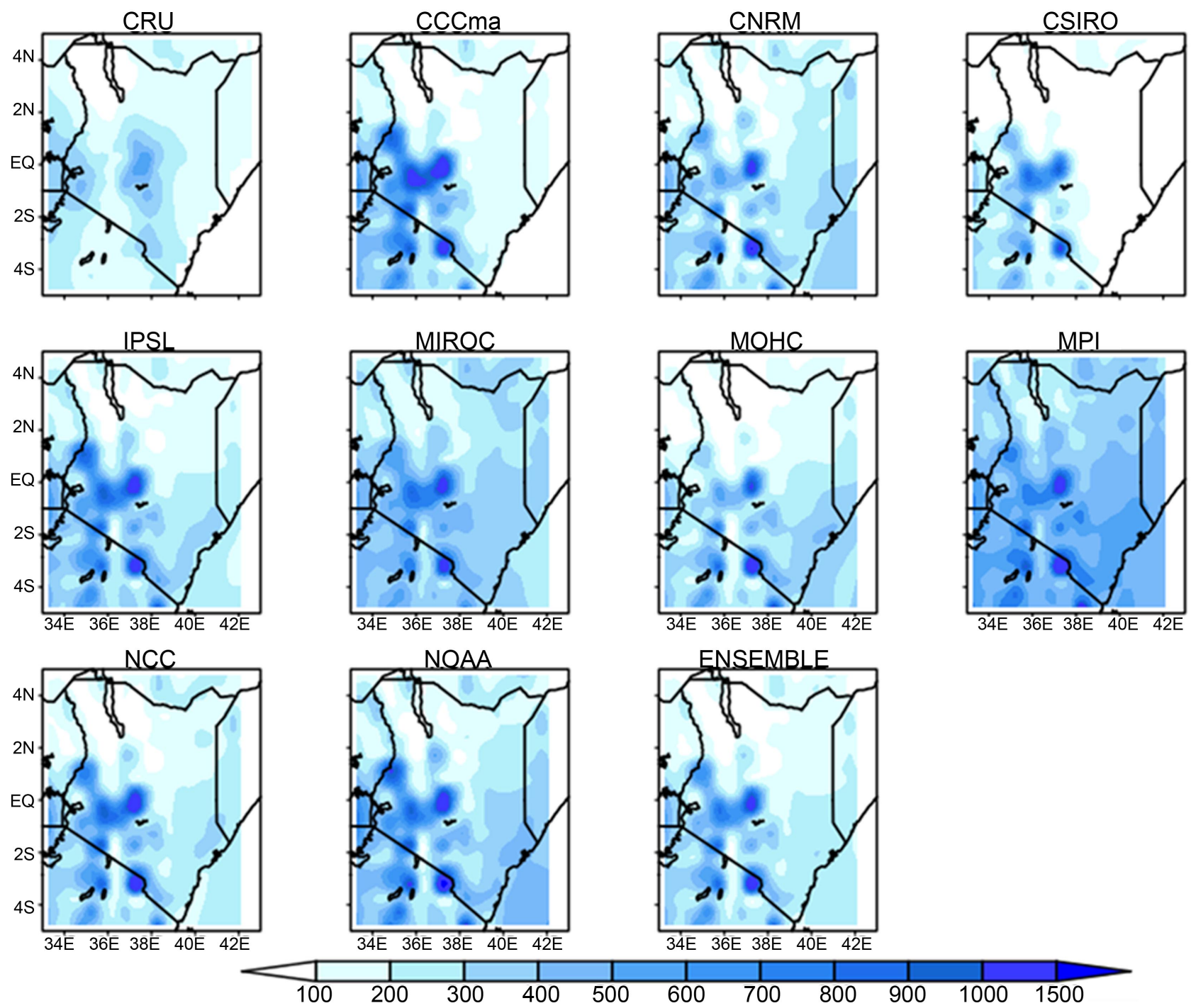

Figure 4. Performance of RCA4 model in simulating the observed OND rainfall total (in mm) over Kenya for 1971-2000. Rainfall amount increases from the white shaded areas through to the red shaded areas.

\subsubsection{Simulated Rainfall Bias against Observed CRU Dataset}

Figure 5 and Figure 6 represent the spatial distribution of the average bias of the simulated rainfall dataset (RCA4) against the observed (CRU) rainfall datasets for the period 1971-2000 during the MAM and OND seasons, respectively. During the MAM season, most of the models underestimate rainfall over most parts of Kenya, especially in the low lying regions. Overestimation of rainfall is mostly noted in the western and central parts of Kenya, particularly around the high altitude areas, by most models except the MOHC, NCC, and NOAA models (Figure 5). Higher positive values of bias were observed during the OND season when compared to the MAM season (Figure 6). Confirming the models tend to overestimate rainfall more during the OND season.

The models' poor skill in the western and central regions can be attributed to their inability to simulate mesoscale systems driven by the orographic drag and the land-water contrasts in these areas. 

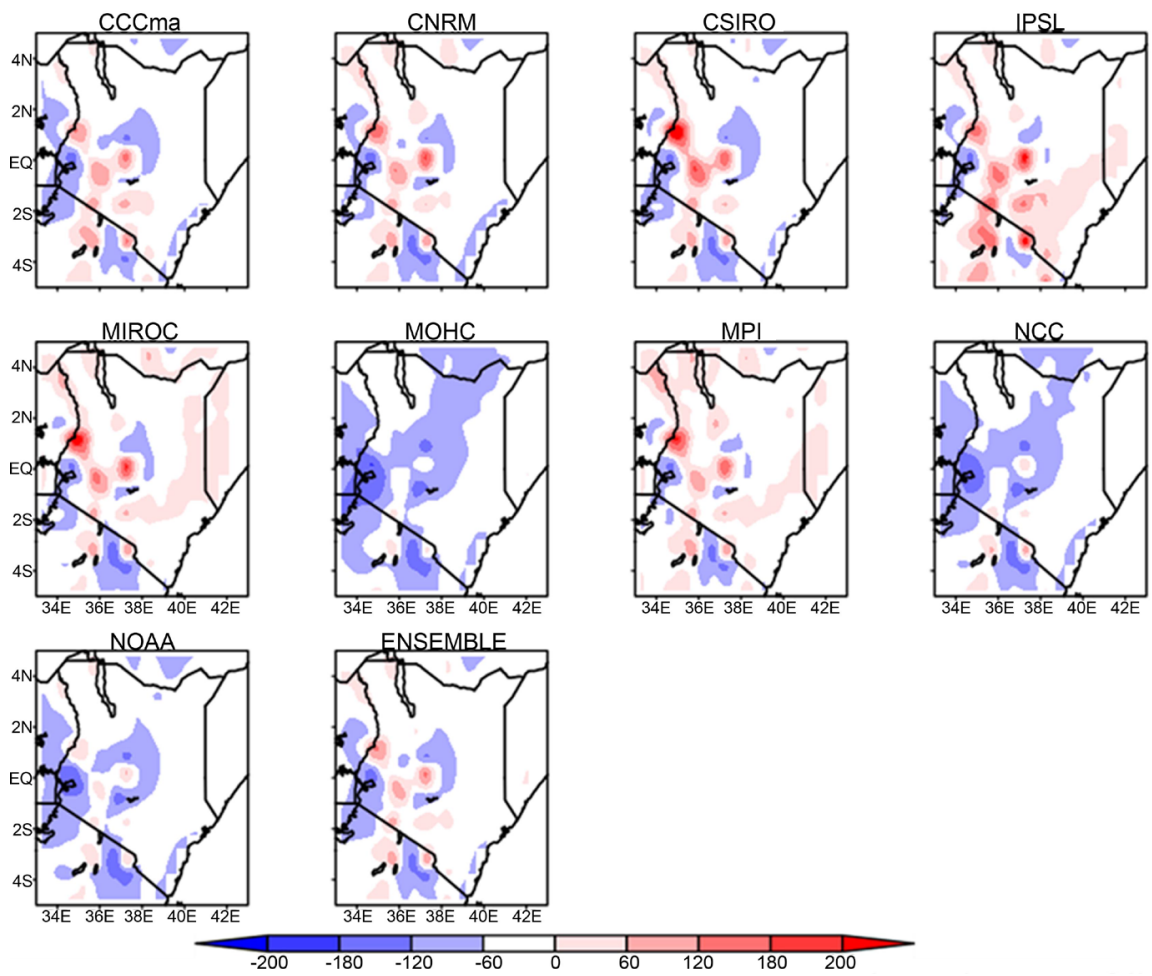

Figure 5. Bias of the average RCA4 simulated rainfall against the observed CRU rainfall for the period 1971-2000 rainfall (in mm) during the MAM season over Kenya. Shades of red indicate overestimation while shades of blue indicate an underestimation.
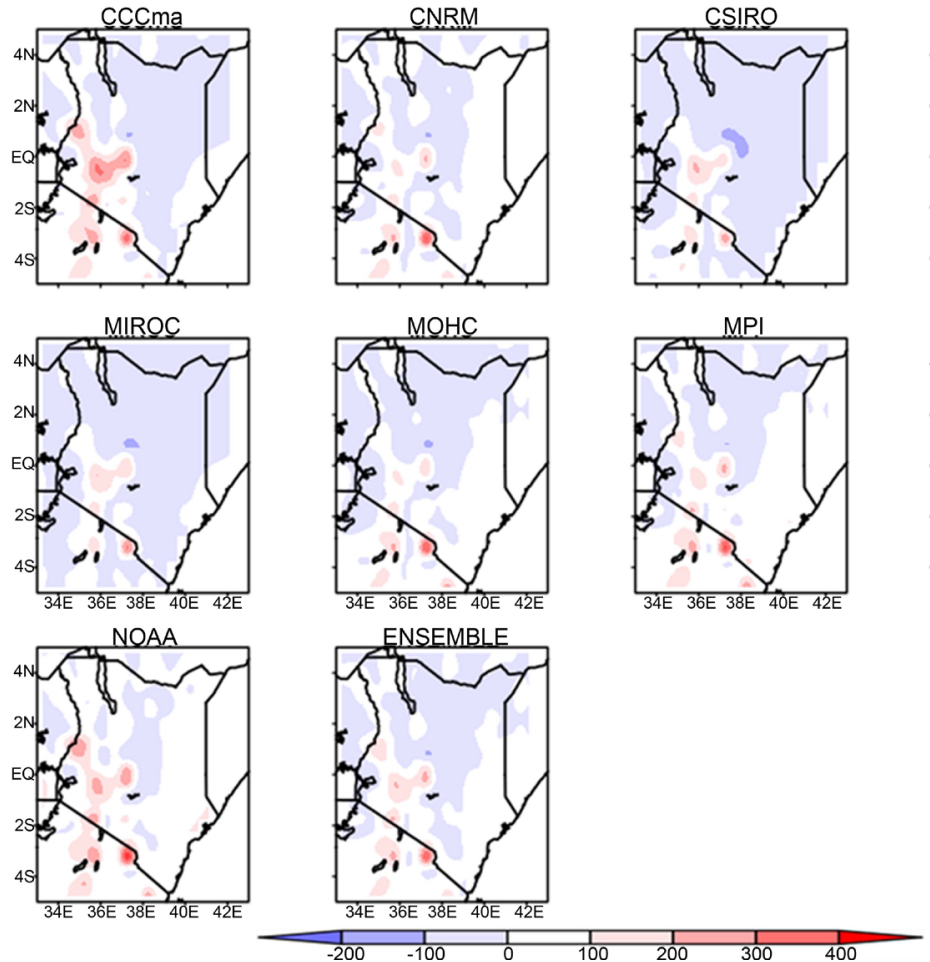

Figure 6. Bias of the average RCA4 simulated rainfall against the observed CRU rainfall for the period 1971-2000 rainfall (in mm) during the OND season over Kenya. Shades of red indicate overestimation while shades of blue indicate an underestimation. 


\subsubsection{Normalised Root Mean Square Error in the Simulated Rainfall Datasets against the Observed (CRU) Rainfall Data}

Figure 7 and Figure 8 represent the spatial distribution of the average NRMSE of the simulated rainfall dataset (RCA4) against the observed (CRU) rainfall datasets for the period 1971-2000 during the MAM and OND seasons, respectively.

Lower values of NRMSE are noted during the MAM season when compared to the OND season over most parts of Kenya. The highest values of NRMSE are noted in the western and central highlands of Kenya and the lowest values in the low altitude area for both seasons. The results agree with earlier observations that models improve accuracy with decreasing altitude.

\subsubsection{Correlation between Simulated Rainfall Datasets and the Observed (CRU) Rainfall Data}

Pearson's correlation between the observed (CRU) and RCA4 model data was evaluated and plotted spatially. Figure 9 and Figure 10 represent the spatial plots of correlation for rainfall during MAM and OND respectively.
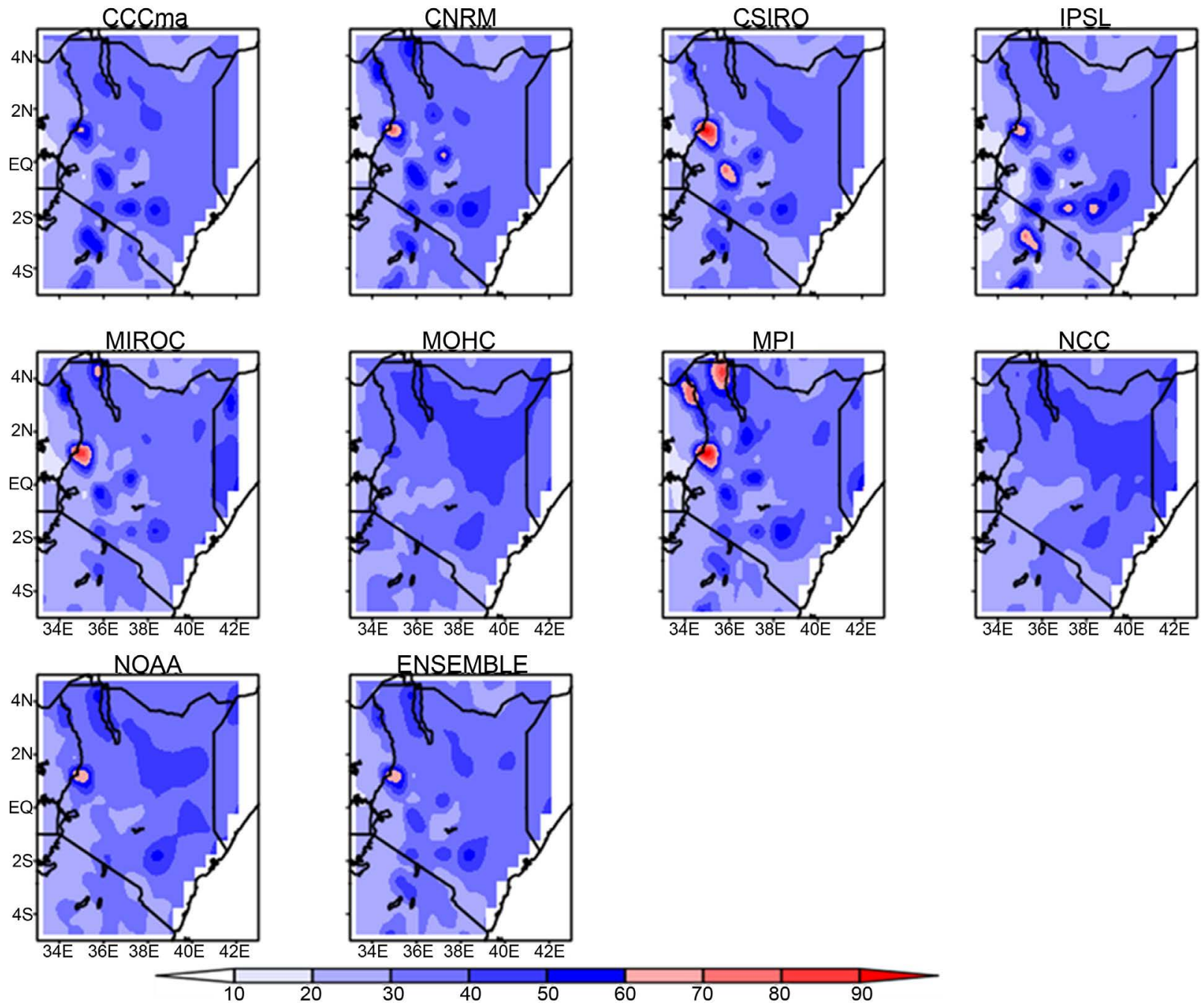

Figure 7. NMRSE of the average RCA4 simulated rainfall against the observed CRU rainfall for the period 1971-2000 rainfall (in \%) during the MAM season over Kenya. Shades of red indicate a large error while shades of blue indicate a small error. 

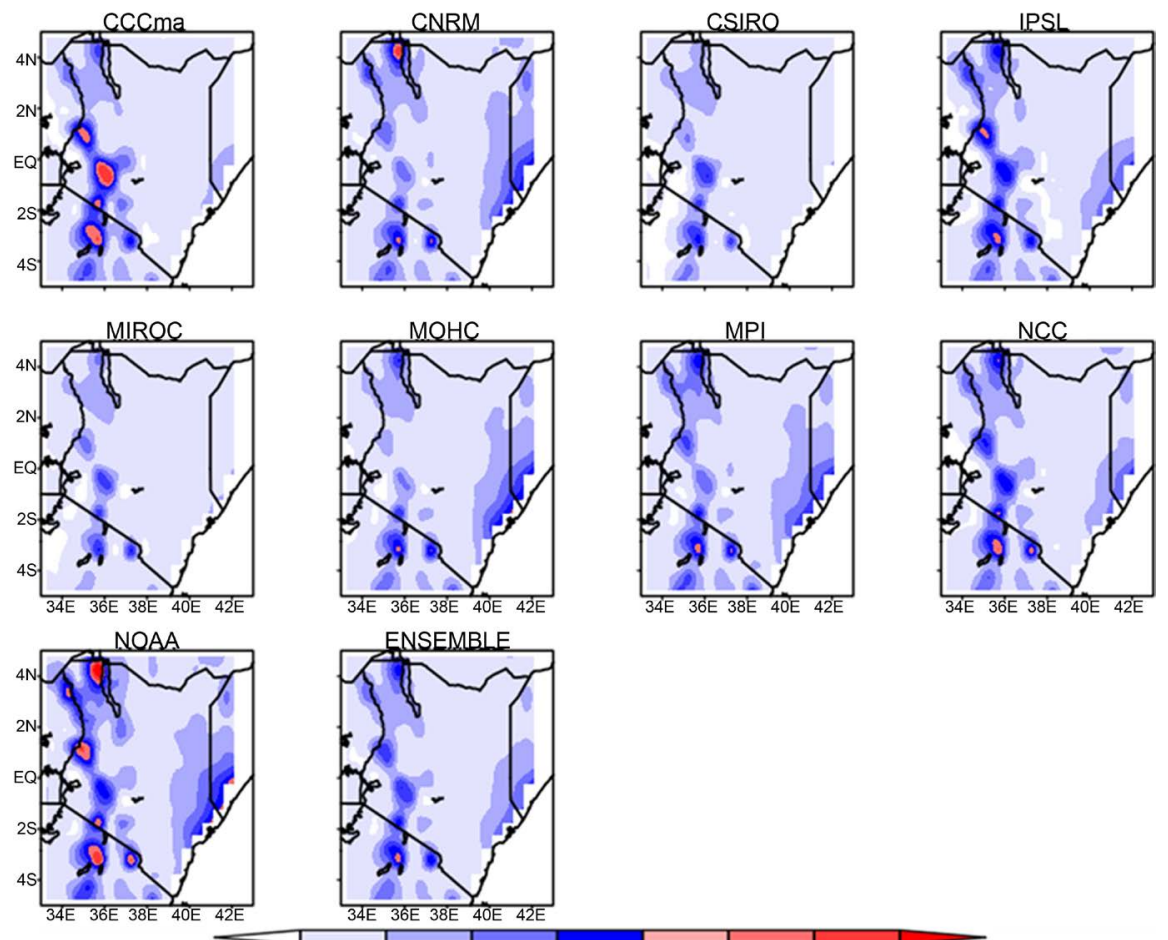

E 36E 38E $40 \mathrm{E} \quad 42 \mathrm{E}$

$34 \mathrm{E} \quad 36 \mathrm{E} \quad 38 \mathrm{E} \quad 40 \mathrm{E} \quad 42 \mathrm{E}$

Figure 8. NMRSE of the average RCA4 simulated rainfall against the observed CRU rainfall for the period 1971-2000 rainfall (in \%) during the OND season over Kenya. Shades of red indicate a large error while shades of blue indicate a small error.
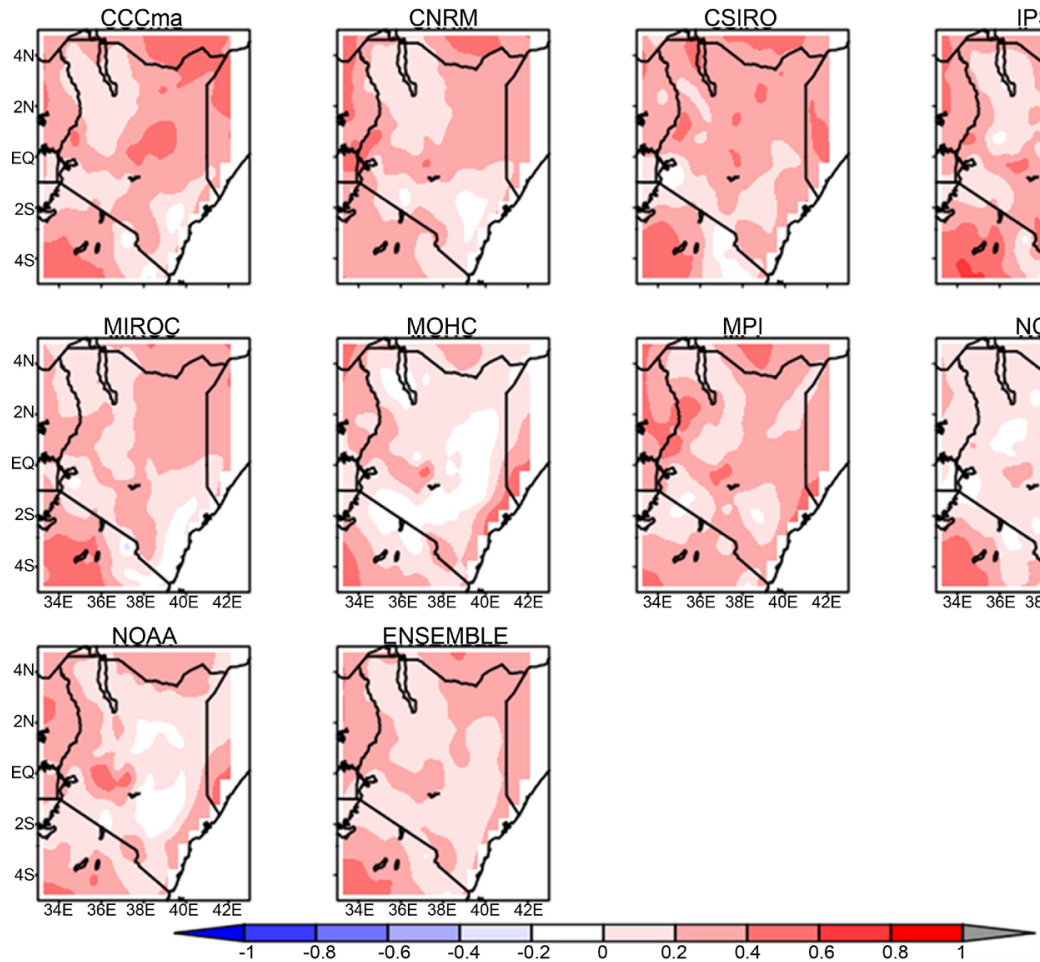

Figure 9. Correlation between observed (CRU) and simulated (RCA4 model) rainfall during the MAM season in the period 1971-2000 over Kenya. Negative (positive) correlation values are represented in shades of blue (red). 

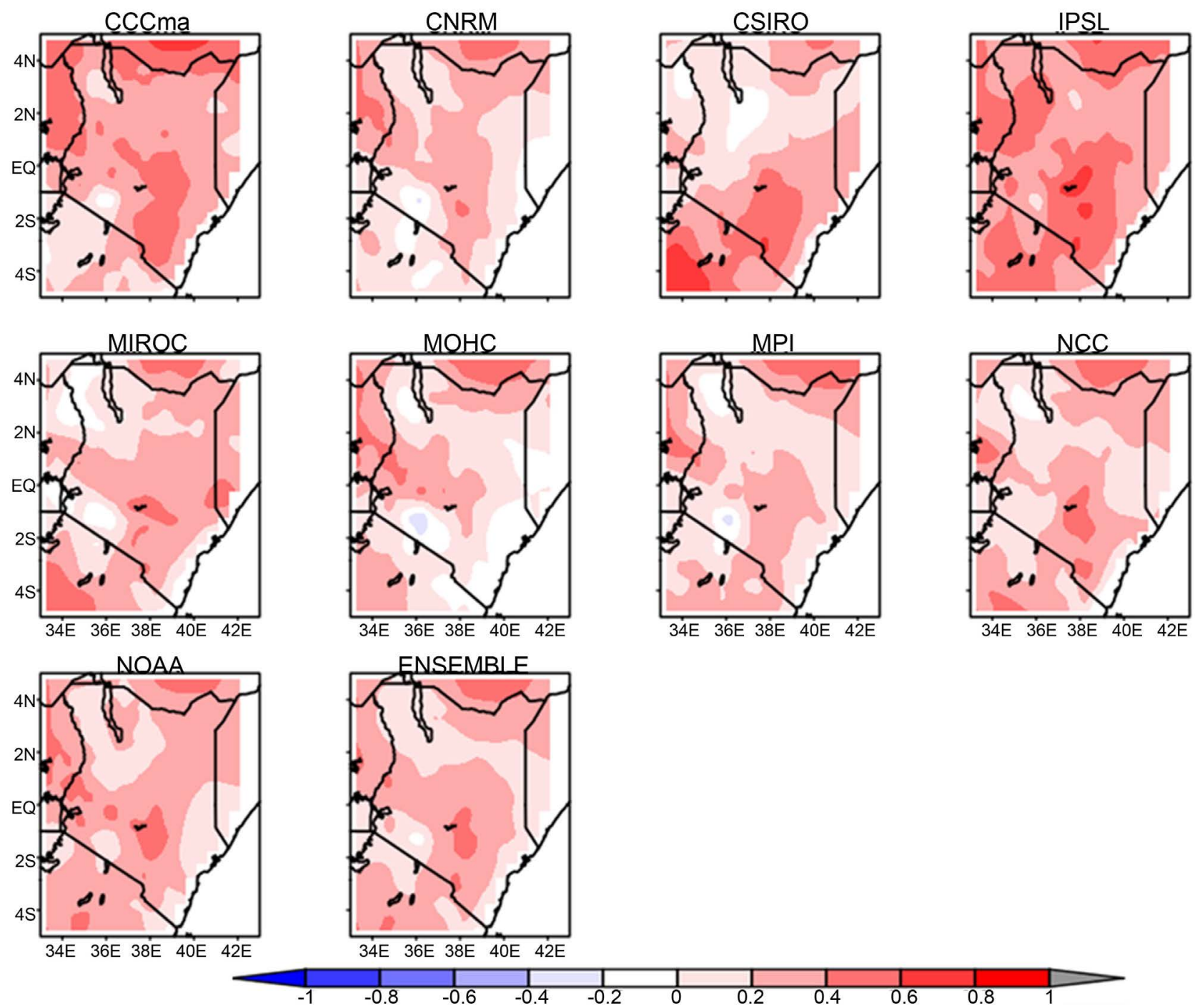

Figure 10. Correlation between observed (CRU) and simulated (RCA4 model) rainfall during the OND season in the period 1971-2000 over Kenya. Negative (positive) correlation values are represented in shades of blue (red).

Overall the correlation between the observed and RCA4 model data was not very good, confirming the models are not able to simulate rainfall in Kenya very well. However, values of correlation greater than +0.2 were observed over several places in the study area during both MAM and OND seasons. Areas around the western and central Kenya show correlation values between -0.2 and +0.2 confirming models are not able to replicate the mesoscale systems around these areas.

\subsection{Bias-Correction of Rainfall during the MAM and OND Rainfall Seasons}

Figure 11 shows the average bias in rainfall after correction during the MAM and OND seasons. Figure 12 represents the average NRMSE in rainfall after correction during the MAM and OND seasons. The MAM and OND season were chosen since they are considered the main rainfall seasons in Kenya. The 


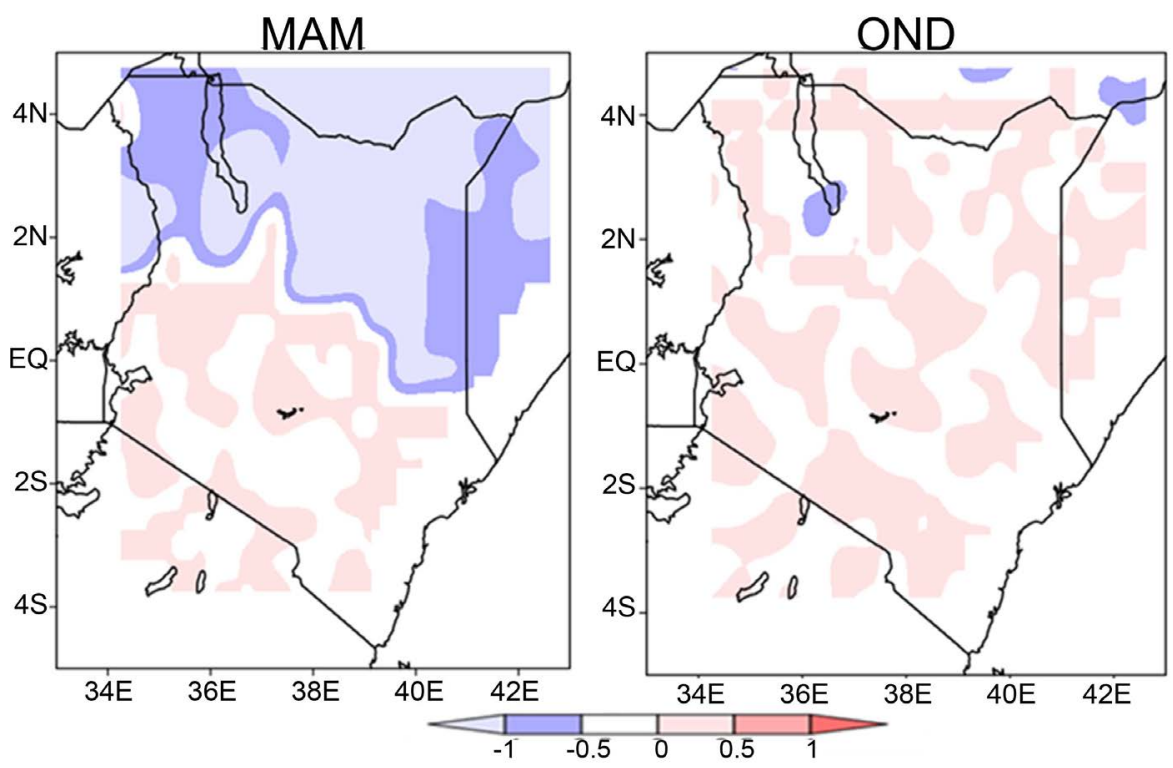

Figure 11. Bias of the average corrected ensemble of simulated rainfall against the observed CRU rainfall for the period 1971-2000 rainfall (in $\mathrm{mm}$ ) during the MAM and OND season over Kenya. Shades of red indicate overestimation while shades of blue indicate an underestimation.

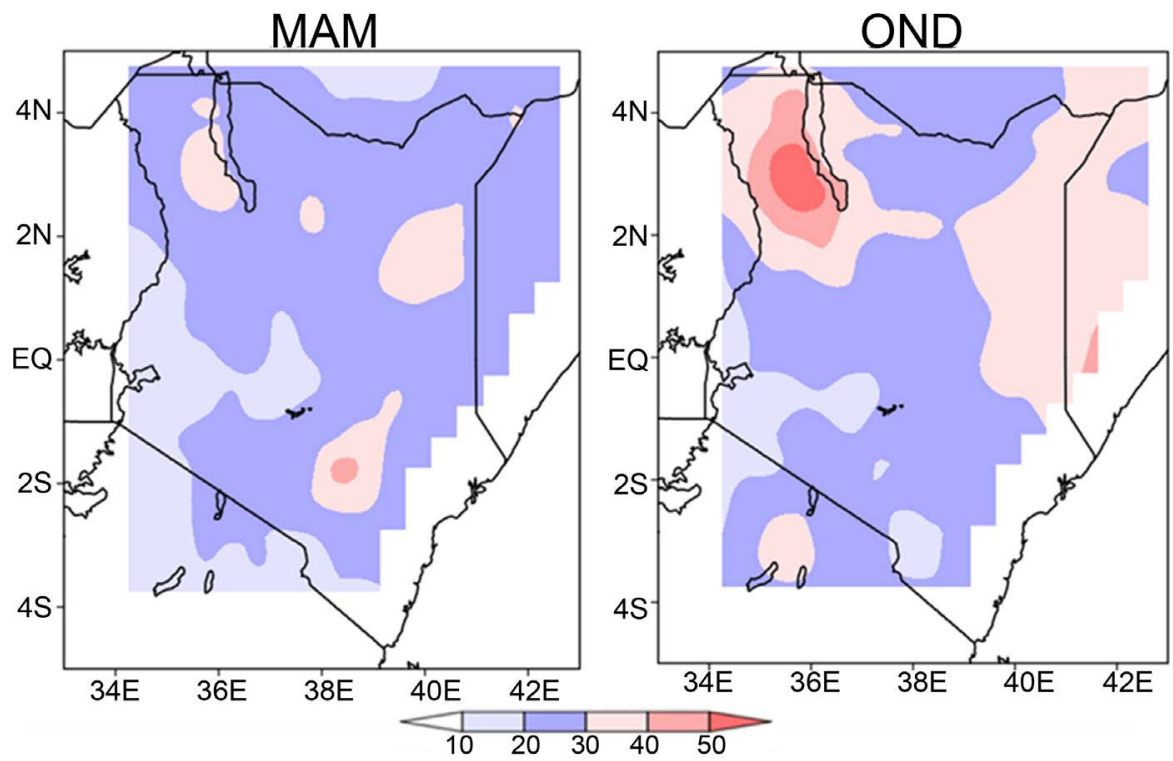

Figure 12. NMRSE of the average RCA4 simulated rainfall against the observed CRU rainfall for the period 1971-2000 rainfall (in \%) during the MAM and OND season over Kenya. Shades of red indicate a large error while shades of blue indicate a small error.

bias-corrected ensemble showed improvement after being corrected during the MAM (Figure 13) and OND (Figure 14) season. Bias correction reduced the disagreement between the observed CRU dataset and the ensemble of the RCA4 RCM dataset. Other studies have found it important to perform bias correction before using the data for climate impact studies (Ezéchiel et al., 2016; Akhter et al., 2017; Mutayoba \& Kashaigili, 2017; Ayugi et al., 2020). 


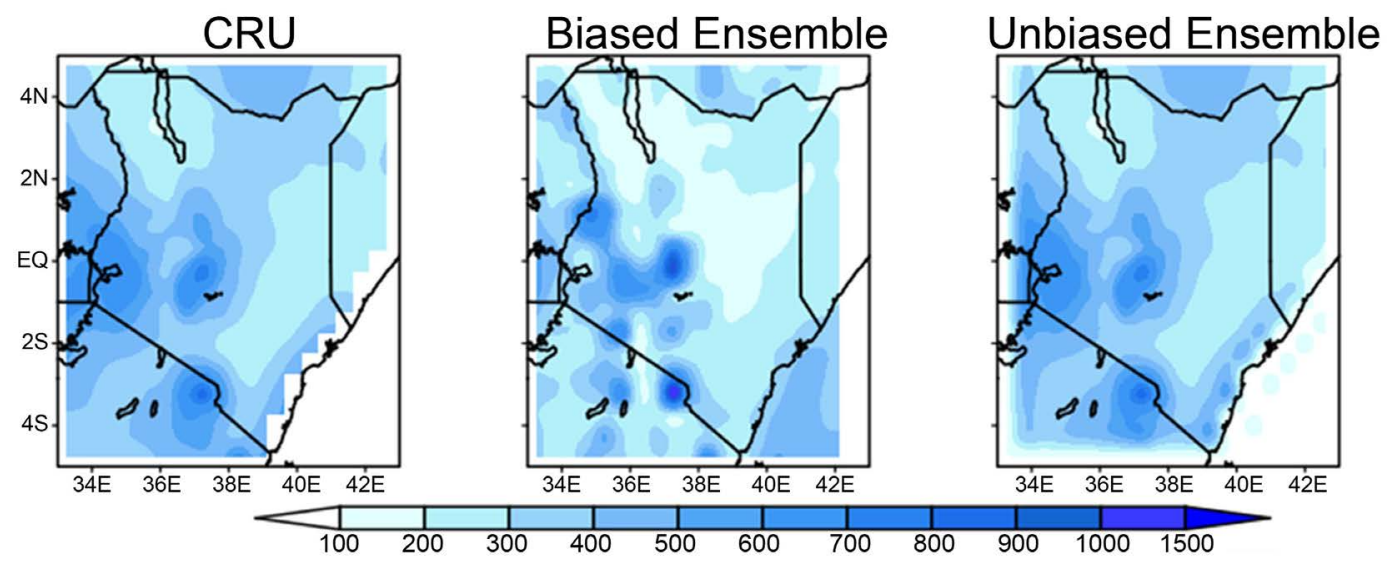

Figure 13. Performance of the RCA4 bias-corrected ensemble in simulating the observed MAM rainfall total (in mm) over Kenya for 1971-2000. Rainfall amount increases from the white shaded areas through to the red shaded areas.

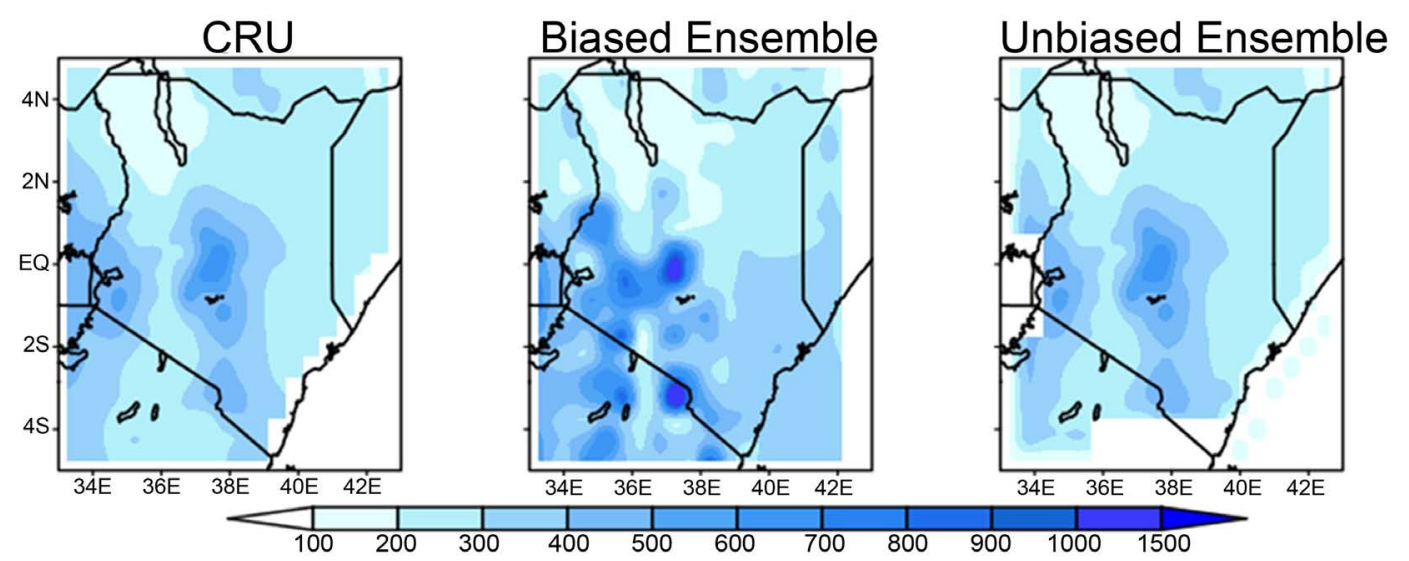

Figure 14. Performance of the RCA4 bias-corrected ensemble in simulating the observed OND rainfall total (in $\mathrm{mm}$ ) over Kenya for 1971-2000. Rainfall amount increases from the white shaded areas through to the red shaded areas.

\subsection{Analysis of Temporal Variability of Seasonal Rainfall Using the Bias-Corrected Ensemble under Baseline and Future Conditions}

Table 2 and Table 3 present the results on the trend of rainfall during the MAM and OND seasons respectively for the baseline, RCP 4.5, and RCP 8.5 scenarios.

The trends in rainfall were statistically insignificant at a $5 \%$ significance level during both MAM and OND seasons under the baseline condition. The insignificance in trend for both seasons means we cannot conclusively determine whether rainfall is increasing or decreasing in these regions and this could be attributed to the variable nature of rainfall. Other studies in the region have also found rainfall to be highly variable (Endris et al., 2016; Ongoma \& Chen, 2017; Sagero et al., 2018). The magnitude of trend change ranged between $-4.4 \%$ and $26.0 \%$ during the MAM season (Table 2) and between $4.0 \%$ and $40.4 \%$ in the OND season (Table 3) for the baseline condition.

During MAM (Table 2) a positive significant trend in rainfall was recorded at 
Table 2. Time series analysis of MAM rainfall $(\mathrm{mm})$ under the baseline, RCP 4.5, and RCP 8.5 scenarios. Where $Z$ symbolizes the Mann Kendall statistic (Bold values mean $Z$ is significant at $95 \%), Q$ symbolizes the Sen's slope and $\% \Delta$ the percentage change of the Sen's slope over mean quantity per unit time.

\begin{tabular}{cccccccccc}
\hline & \multicolumn{3}{c}{ Baseline } & \multicolumn{3}{c}{ RCP 4.5 } & \multicolumn{3}{c}{ RCP 8.5 } \\
\hline Station & $\mathrm{Z}$ & $\mathrm{Q}$ & $\% \Delta$ & $\mathrm{Z}$ & $\mathrm{Q}$ & $\% \Delta$ & $\mathrm{Z}$ & $\mathrm{Q}$ & $\% \Delta$ \\
\hline Dagoretti & 1.4 & 1.9 & 12.5 & 1.4 & 2.9 & 18.5 & -0.8 & -1 & -6.3 \\
Garissa & 1.2 & 0.6 & 12.6 & 1.9 & 3.8 & 61.7 & 0.6 & 0.7 & 10.6 \\
Kakamega & 1.2 & 2.6 & 12.3 & -0.1 & -0.6 & -2.7 & 0.2 & 0.9 & 3.7 \\
Kisumu & 1 & 1.7 & 9.4 & -1 & -4 & -21.2 & 0.5 & 0.7 & 3.7 \\
Lamu & $\mathrm{NA}$ & $\mathrm{NA}$ & $\mathrm{NA}$ & $\mathrm{NA}$ & $\mathrm{NA}$ & $\mathrm{NA}$ & $\mathrm{NA}$ & $\mathrm{NA}$ & $\mathrm{NA}$ \\
Mandera & 0.6 & 0.3 & 5.9 & 2.7 & $\mathbf{3 . 6}$ & 56.8 & 2.5 & 3.1 & 42.8 \\
Marsabit & 0.6 & 0.6 & 7.6 & 2.8 & $\mathbf{6 . 9}$ & 73 & 2.9 & 3.8 & 37.9 \\
Mombasa & $\mathrm{NA}$ & $\mathrm{NA}$ & $\mathrm{NA}$ & $\mathrm{NA}$ & $\mathrm{NA}$ & $\mathrm{NA}$ & $\mathrm{NA}$ & $\mathrm{NA}$ & $\mathrm{NA}$ \\
Moyale & 0 & 0 & 0.3 & 2.8 & $\mathbf{3 . 8}$ & 37.2 & 2.9 & 3.8 & 35.3 \\
Nakuru & 0.2 & 0.3 & 2.7 & -0.6 & -1 & -10.3 & 0 & 0 & -0.3 \\
Nanyuki & 0.4 & 0.5 & 3.9 & 1.9 & 2.8 & 21.8 & -1 & -0.8 & -6 \\
Narok & 1 & 1.7 & 14.7 & -0.4 & -1 & -8.5 & -0.7 & -0.8 & -6.4 \\
Voi & -0.6 & -0.3 & -4.4 & 2.1 & $\mathbf{3 . 2}$ & 38.4 & -0.2 & -0.2 & -2.5 \\
Wajir & 1.8 & 1.5 & 26 & 3.9 & $\mathbf{5 . 9}$ & 85.1 & $\mathbf{2}$ & 1.7 & 23.4 \\
Lodwar & 0.9 & 0.5 & 16 & 1.7 & 2.4 & 55.2 & 2.1 & 2.4 & 52.6 \\
Kitui & 1.4 & 1.6 & 14.2 & 2.5 & $\mathbf{5 . 7}$ & 46.4 & -0.7 & -0.8 & -5.9 \\
\hline
\end{tabular}

Table 3. Time series analysis of OND rainfall $(\mathrm{mm})$ under the baseline, RCP 4.5, and RCP 8.5 scenarios. Where $\mathrm{Z}$ symbolizes the Mann Kendall statistic (Bold values means $Z$ is significant at 95\%), $Q$ symbolizes the Sen's slope and $\% \Delta$ the percentage change of the Sen's slope over mean quantity per unit time.

\begin{tabular}{cccccccccc}
\hline & \multicolumn{3}{c}{ Baseline } & \multicolumn{3}{c}{ RCP 4.5 } & \multicolumn{3}{c}{ RCP 8.5 } \\
\hline Station & $\mathrm{Z}$ & $\mathrm{Q}$ & $\% \Delta$ & $\mathrm{Z}$ & $\mathrm{Q}$ & $\% \Delta$ & $\mathrm{Z}$ & $\mathrm{Q}$ & $\% \Delta$ \\
\hline Dagoretti & 0.4 & 0.4 & 4 & 1.9 & 1.7 & 16.9 & 1 & 0.8 & 8.3 \\
Garissa & 1.4 & 0.5 & 9.3 & 1.7 & 1.9 & 26.4 & 0.9 & 1 & 13.8 \\
Kakamega & 1 & 2 & 16.5 & 2.1 & 3.5 & 24.9 & 0.5 & 0.9 & 6.3 \\
Kisumu & 1.1 & 1.6 & 15.5 & 1.3 & 2 & 17.6 & -0.3 & -0.6 & -5.7 \\
Lamu & $\mathrm{NA}$ & $\mathrm{NA}$ & $\mathrm{NA}$ & $\mathrm{NA}$ & $\mathrm{NA}$ & $\mathrm{NA}$ & $\mathrm{NA}$ & $\mathrm{NA}$ & $\mathrm{NA}$ \\
Mandera & 1.2 & 0.5 & 11.6 & 1.4 & 1.3 & 27.3 & 1.8 & 1.4 & 25.8 \\
Marsabit & 0.5 & 0.5 & 8.5 & 1.8 & 2 & 26.8 & 2.3 & 2.2 & 27.5 \\
Mombasa & $\mathrm{NA}$ & $\mathrm{NA}$ & $\mathrm{NA}$ & $\mathrm{NA}$ & $\mathrm{NA}$ & $\mathrm{NA}$ & $\mathrm{NA}$ & $\mathrm{NA}$ & $\mathrm{NA}$ \\
Moyale & 0.8 & 0.5 & 8.6 & 0.9 & 1.3 & 17.2 & 2.2 & 2.1 & 27.5 \\
Nakuru & 0.9 & 0.4 & 6.1 & 1 & 0.4 & 6.4 & -0.4 & -0.1 & -1.2 \\
Nanyuki & 1.2 & 1 & 6.6 & 1.3 & 1.5 & 9.8 & 0.9 & 0.6 & 3.7 \\
Narok & 0.4 & 0.2 & 4.1 & 1.3 & 0.8 & 13.2 & 0 & 0 & 0.5 \\
Voi & 0.5 & 0.2 & 2.6 & 1.6 & 1.7 & 17.6 & 1.1 & 1.1 & 10.8 \\
Wajir & 1.6 & 0.8 & 18.5 & 1.8 & 1.7 & 30.5 & 1.8 & 1.4 & 24.3 \\
Lodwar & 1.4 & 0.6 & 40.4 & 2.2 & 0.9 & 51.6 & 1 & 0.5 & 24.5 \\
Kitui & 1 & 0.8 & 6 & 1.6 & 2.2 & 13.7 & 1.1 & 1.7 & 10 \\
\hline
\end{tabular}


the Mandera, Marsabit, Moyale, Voi, Wajir, and Kitui stations under the RCP 4.5 scenario, and at Mandera, Marsabit, Moyale, Wajir and Lodwar under the RCP 8.5 scenario. The magnitude of trend ranged between $-8.5 \%$ and $85.1 \%$ under the RCP 4.5 scenario, and between $-6.4 \%$ and $52.6 \%$ under the RCP 8.5 scenario.

During OND (Table 3) a positive significant trend in rainfall was recorded at the Kakamega and Lodwar stations under the RCP 4.5 scenario, and at Marsabit and Moyale under the RCP 8.5 scenario. The magnitude of trend ranged between $6.4 \%$ and $51.6 \%$ under the RCP 4.5 scenario, and between $-5.7 \%$ and $27.5 \%$ under the RCP 8.5 scenario.

The positive trend recorded under RCP 4.5 and 8.5 show rainfall will increase in the future. Some studies using CMIP3/5 data found rainfall will increase in the future over East Africa as a result of global warming due to increased anthropogenic emissions of greenhouse gases (Otieno \& Anyah, 2013; Tierney et al., 2015). However, other studies using observed data found a decrease in observed rainfall over East Africa during the MAM season and a wetter OND season (Ongoma \& Chen, 2017; Ongoma et al., 2018; Mumo et al., 2019). The increase in OND rainfall was attributed to the warming of the western Indian Ocean (Liebmann et al., 2014). Yang et al. (2014) attributed the decrease in MAM rainfall over East Africa to natural decadal variability rather than anthropogenic influence.

The inconsistency between the observed conditions and the global model predictions is called the "East Africa climate paradox" (Rowell et al., 2015). The disagreement between observed and model data trends has been attributed to the scarcity of in situ data required for model parameterization over the region (Brands et al., 2013). If the projected rainfall actualizes, it will be a recovery from the observed drying trend currently being experienced (Yang et al., 2015).

\subsection{Spatial Analysis of Seasonal Rainfall Using the Bias-Corrected Ensemble under Baseline and Future Conditions}

Figure 15 and Figure 16 represent the spatial analysis of rainfall during the MAM and OND seasons based on RCP 4.5 and RCP 8.5 scenario for the period from 2021 to 2050 .

Figure 15 and Figure 16 show that the rainfall is concentrated in the western and central parts of the country during both the MAM and OND seasons. The spatial trend in rainfall is expected to increase in area under both RCP 4.5 and RCP 8.5 scenario when compared to the baseline; the area increase is higher under the RCP 8.5 scenario. The rainfall amount increase in the MAM season is more compared to the OND season for both RCP 4.5 and 8.5 scenarios. Mukhala et al. (2017) found small precipitation gains in the future in a similar study, using the uncorrected MME of the RCA4 model. 


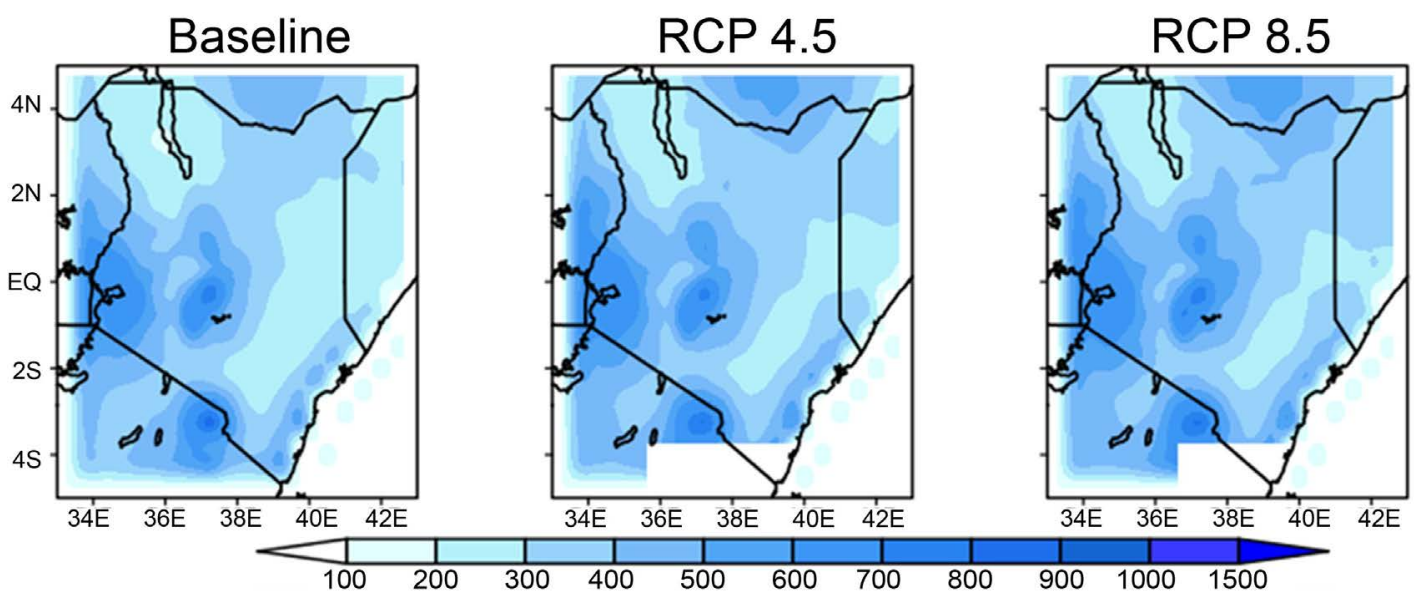

Figure 15. Spatial analysis of rainfall during the MAM season based on RCP 4.5 and RCP 8.5 scenario (2021-2050). Rainfall amount increases from the white shaded areas through to the blue shaded areas.

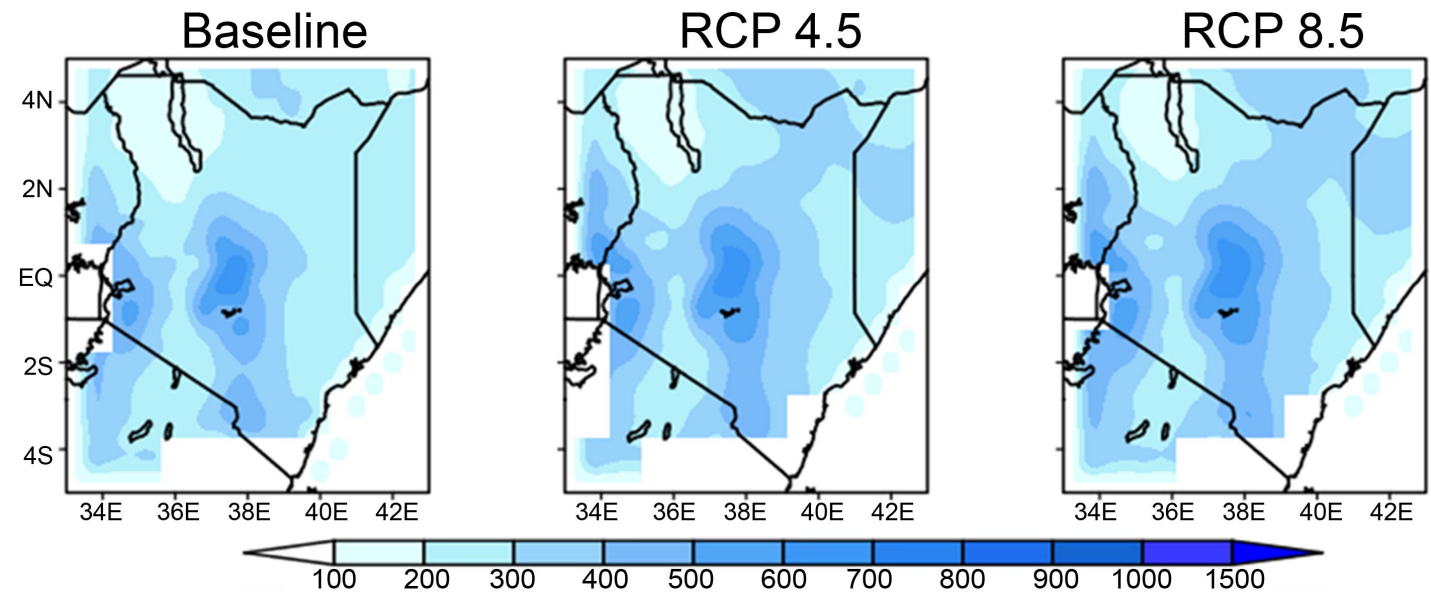

Figure 16. Spatial analysis of rainfall during the OND season based on RCP 4.5 and RCP 8.5 scenario (2021-2050). Rainfall amount increases from the white shaded areas through to the blue shaded areas.

\section{Conclusion}

The pattern and distribution of rainfall in Kenya drive farming practices and agricultural policies and the behaviour of rainfall in the future will affect the agricultural industry in the country. This study sought to investigate the spatial and temporal variability of rainfall under past and future climate scenarios. To achieve this objective a suite of models downscaled by the RCA4 model and observed CRU data was used to assess the present and future rainfall patterns over Kenya. Since the skill of the individual and ensemble of RCA4 models over the domain was not very good in replicating rainfall in Kenya for the MAM and OND seasons; the skill was improved by reducing the error in the ensemble using the scaling method.

The bias-corrected ensemble showed improvement in simulating the rainfall for the two seasons was consequently used to study rainfall variability relative to the baseline period under future RCP 4.5 and RCP 8.5 scenarios. An insignificant trend was noted under the baseline condition during the March-May 
(MAM) and October-December (OND) rainfall seasons. A positive significant trend at 5\% level was noted under RCP 4.5 and 8.5 scenarios in some stations during both MAM and OND seasons. The increase in rainfall was attributed to global warming due to increased anthropogenic emissions of greenhouse gases. Results on the spatial variability of rainfall indicate the spatial extent of rainfall will increase under both RCP 4.5 and RCP 8.5 scenario when compared to the baseline; the increase is higher under the RCP 8.5 scenario.

Overall the bias-corrected ensemble of the RCA4 model was able to capture the pattern of MAM and OND rainfall in Kenya and can be used for further studies. Rainfall was found to be highly variable in space and time and there is thus need to invest in the early dissemination of weather forecasts to help farmers adequately prepare in case of unfavourable weather. Concerning the expected increase in rainfall in the future, policymakers need to consider the results of this study while preparing mitigation strategies against the effects of changing rainfall patterns.

\section{Acknowledgements}

This research paper is part of the $\mathrm{PhD}$ thesis for the lead author at the University of Nairobi, Kenya. The authors acknowledge sources of data used as provided by the Kenya Meteorological Department, Climate Research Unit (CRU) and Coordinated Regional Downscaling Experiment (CORDEX). The lead author expresses appreciation to the German Academic Exchange Service (DAAD) scholarship for the financial support.

\section{Conflicts of Interest}

The authors declare no conflicts of interest regarding the publication of this paper.

\section{References}

Adhikari, U., Nejadhashemi, A. P., \& Woznicki, S. A. (2015). Climate Change and Eastern Africa: A Review of Impact on Major Crops. Food and Energy Security, 4, 110-132. https://doi.org/10.1002/fes3.61

Akhter, J., Das, L., \& Deb, A. (2017). CMIP5 Ensemble-Based Spatial Rainfall Projection over Homogeneous Zones of India. Climate Dynamics, 49, 1885-1916. https://doi.org/10.1007/s00382-016-3409-8

Ayugi, B. et al. (2020). Quantile Mapping Bias Correction on Rossby Centre Regional Climate Models for Precipitation Analysis over Kenya, East Africa. Water (Switzerland), 12, 1-16. https://doi.org/10.3390/w12030801

Ayugi, B. O., Wang, W., \& Chepkemoi, D. (2016). Analysis of Spatial and Temporal Patterns of Rainfall Variations over Kenya. Environment and Earth Science, 6, 69-83.

Bobadoye, A., Ogara, W. O., \& Onono, J. O. (2014). Comparative Analysis of Rainfall Trends in Different Sub Counties in Kajiado County Kenya. International Journal of Innovative Research and Studies, 12, 179-195.

Brands, S., Herrera, S., Fernández, J., \& Gutiérrez, J. M. (2013). How Well Do CMIP5 Earth System Models Simulate Present Climate Conditions in Europe and Africa? A Perfor- 
mance Comparison for the Downscaling Community. Climate Dynamics, 41, 803-817. https://doi.org/10.1007/s00382-013-1742-8

Clarke, L., Edmonds, J., Krey, V., Richels, R., Rose, S., \& Tavoni, M. (2009). International Climate Policy Architectures: Overview of the EMF 22 International Scenarios. Energy Economics, 31, 64-81. https://doi.org/10.1016/j.eneco.2009.10.013

Duhan, D., \& Pandey, A. (2013). Statistical Analysis of Long Term Spatial and Temporal Trends of Precipitation during 1901-2002 at Madhya Pradesh, India. Atmospheric Research, 122, 136-149. https://doi.org/10.1016/j.atmosres.2012.10.010

El-Beltagy, A., \& Madkour, M. (2012). Impact of Climate Change on Arid Lands Agriculture. Agriculture \& Food Security, 1, Article No. 3.

https://doi.org/10.1186/2048-7010-1-3

Endris, H. S. et al. (2013). Assessment of the Performance of CORDEX Regional Climate Models in Simulating East African Rainfall. Journal of Climate, 26, 8453-8475. https://doi.org/10.1175/JCLI-D-12-00708.1

Endris, H. S., Lennard, C., Hewitson, B., Dosio, A., Nikulin, G., \& Panitz, H. J. (2016). Teleconnection Responses in Multi-GCM Driven CORDEX RCMs over Eastern Africa. Climate Dynamics, 46, 2821-2846. https://doi.org/10.1007/s00382-015-2734-7

Eriksen, S. H., Brown, K., \& Kelly, P. M. (2005). The Dynamics of Vulnerability: Locating Coping Strategies in Kenya and Tanzania. Geographical Journal, 171, 287-305. https://doi.org/10.1111/j.1475-4959.2005.00174.x

Ezéchiel, O., Eric, A. A., Josué, Z. E., Eliézer, B. I., \& Amédée, C. (2016). Comparative Study of Seven Bias Correction Methods Applied to Three Regional Climate Models in Mekrou Catchment (Benin, West Africa). International Journal of Current Engineering and Technology, 6, 1831-1840.

Harris, I., Jones, P. D., Osborn, T. J., \& Lister, D. H. (2014). Updated High-Resolution Grids of Monthly Climatic Observations-The CRU TS3.10 Dataset. International Journal of Climatology, 34, 623-642. https://doi.org/10.1002/joc.3711

Herrero, M., Ringler, C., Steeg, J. Van De, Koo, J., \& Notenbaert, A. (2010). Climate Variability and Climate Change and Their Impacts on Kenya's Agricultural Sector. Nairobi.

Holzkämper, A., Calanca, P., \& Fuhrer, J. (2011). Analyzing Climate Effects on Agriculture in Time and Space. Procedia Environmental Sciences, 3, 58-62. https://doi.org/10.1016/j.proenv.2011.02.011

Indeje, M., Semazzi, F. H. M., \& Ogallo, L. J. (2000). ENSO Signals in East African Rainfall Seasons. International Journal of Climatology, 20, 19-46. https://doi.org/10.1002/(SICI)1097-0088(200001)20:1<19::AID-JOC449>3.0.CO;2-0

Indeje, M., Semazzi, F. H. M., Xie, L., \& Ogallo, L. J. (2001). Mechanistic Model Simulations of the East African Climate Using NCAR Regional Climate Model: Influence of Large-Scale Orography on the Turkana Low-Level Jet. Journal of Climate, 14, 27102724. https://doi.org/10.1175/1520-0442(2001)014<2710:MMSOTE >2.0.CO;2

Kendall, M. (1975). Rank Correlation Methods (4th ed.). London: Charles Griffin.

Kisembe, J., Favre, A., Dosio, A., Lennard, C., Sabiiti, G., \& Nimusiima, A. (2019). Evaluation of Rainfall Simulations over Uganda in CORDEX Regional Climate Models. Theoretical and Applied Climatology, 137, 1117-1134.

https://doi.org/10.1007/s00704-018-2643-x

Liebmann, B., Hoerling, M. P., Funk, C., Bladé, I., Dole, R. M., Allured, D., Quan, X., Pegion, P., \& Eischeid, J. K. (2014). Understanding Recent Eastern Horn of Africa Rainfall Variability and Change. Journal of Climate, 27, 8630-8645. 
https://doi.org/10.1175/JCLI-D-13-00714.1

Liu, H., Chen, J., Zhang, X.-C., Xu, C.-Y., \& Hui, Y. (2020). A Markov Chain-Based Bias Correction Method for Simulating the Temporal Sequence of Daily Precipitation. Atmosphere, 11, 1-17. https://doi.org/10.3390/atmos11010109

Luhunga, P., Botai, J., \& Kahimba, F. (2016). Evaluation of the Performance of CORDEX Regional Climate Models in Simulating Present Climate Conditions of Tanzania. Journal of Southern Hemisphere Earth System Science, 66, 32-54. https://doi.org/10.22499/3.6601.005

Mann, H. B. (1945). Nonparametric Tests against Trend. Econometrica, 13, 245-259. https://doi.org/10.2307/1907187

Mugo, J. W., Kariuki, P. C., \& Musembi, D. K. (2016). Identification of Suitable Land for Green Gram Production Using GIS Based Analytical Hierarchy Process in Kitui County, Kenya. Journal of Remote Sensing \& GIS, 5, 1-7. https://doi.org/10.4172/2469-4134.1000170

Mukhala, E., Ngaina, J. N., \& Maingi, N. W. (2017). Downscaled Climate Analysis on Historical, Current and Future Trends in the East African Community Region. Nairobi: Kenya Institute for Policy Research and Analysis (KIPPRA).

Mumo, L., Yu, J., \& Ayugi, B. (2019). Evaluation of Spatiotemporal Variability of Rainfall over Kenya from 1979 to 2017. Journal of Atmospheric and Solar-Terrestrial Physics, 194, Article ID: 105097. https://doi.org/10.1016/j.jastp.2019.105097

Mutayoba, E., \& Kashaigili, J. J. (2017). Evaluation for the Performance of the CORDEX Regional Climate Models in Simulating Rainfall Characteristics over Mbarali River Catchment in the Rufiji Basin, Tanzania. Journal of Geoscience and Environment Protection, 5, 139-151. https://doi.org/10.4236/gep.2017.54011

Ochieng, J., Kirimi, L., \& Mathenge, M. (2016). Effects of Climate Variability and Change on Agricultural Production: The Case of Small Scale Farmers in Kenya. NJAS Wageningen Journal of Life Sciences, 77, 71-78. https://doi.org/10.1016/j.njas.2016.03.005

Ogega, O. M., Oludhe, C., Ojwang, L., \& Mbugua, J. (2016). Localized Knowledge for Local Climate Change Adaptation: A Focus on Coastal Smallholder Farmers in Kenya. International Journal of Agriculture, Environment and Biotechnology, 1, 67-88.

Okoola, R. E. (1999). Midtropospheric Circulation Patterns Associated with Extreme Dry and Wet Episodes over Equatorial Eastern Africa during the Northern Hemisphere Spring. Journal of Applied Meteorology, 38, 1161-1169. https://doi.org/10.1175/1520-0450(1999)038<1161:MCPAWE >2.0.CO;2

Omeny, P. A., Okoola, R., Hendon, H., \& Wheeler, M. (2008). East African Rainfall Variability Associated with the Madden-Julian Oscillation. Journal of Kenya Meteorological Society, 2, 105-114.

Omoyo, N. N., Wakhungu, J., \& Oteng'i, S. (2015). Effects of Climate Variability on Maize Yield in the Arid and Semi Arid Lands of Lower Eastern Kenya. Agriculture and Food Security, 4, 1-13. https://doi.org/10.1186/s40066-015-0028-2

Ongoma, V., \& Chen, H. (2017). Temporal and Spatial Variability of Temperature and Precipitation over East Africa from 1951 to 2010. Meteorology and Atmospheric Physics, 129, 131-144. https://doi.org/10.1007/s00703-016-0462-0

Ongoma, V., Chen, H., \& Gao, C. (2019). Evaluation of CMIP5 Twentieth Century Rainfall Simulation over the Equatorial East Africa. Theoretical and Applied Climatology, 135, 893-910. https://doi.org/10.1007/s00704-018-2392-x

Ongoma, V., Chen, H., \& Omony, G. W. (2018). Variability of Extreme Weather Events over the Equatorial East Africa, a Case Study of Rainfall in Kenya and Uganda. Theo- 
retical and Applied Climatology, 131, 295-308.

https://doi.org/10.1007/s00704-016-1973-9

Ongoma, V., Guirong, T., Ogwang, B., \& Ngarukiyimana, J. (2015). Diagnosis of Seasonal Rainfall Variability over East Africa: A Case Study of 2010-2011 Drought over Kenya. Pakistan Journal of Meteorology, 11, 13-21.

Otieno, V. O., \& Anyah, R. O. (2013). CMIP5 Simulated Climate Conditions of the Greater Horn of Africa (GHA). Part 1: Contemporary Climate. Climate Dynamics, 41, 20812097. https://doi.org/10.1007/s00382-012-1549-Z

Ouma, J. O., Olang, L. O., Ouma, G. O., Oludhe, C., Ogallo, L., \& Artan, G. (2018). Magnitudes of Climate Variability and Changes over the Arid and Semi-Arid Lands of Kenya between 1961 and 2013 Period. American Journal of Climate Change, 7, 27-39. https://doi.org/10.4236/ajcc.2018.71004

Riahi, K., Rao, S., Krey, V., Cho, C., Chirkov, V., Fischer, G., Kindermann, G., Nakicenovic, N., \& Rafaj, P. (2011). RCP 8.5-A Scenario of Comparatively High Greenhouse Gas Emissions. Climatic Change, 109, 33-57. https://doi.org/10.1007/s10584-011-0149-y

Rowell, D. P., Booth, B. B. B., Nicholson, S. E., \& Good, P. (2015). Reconciling Past and Future Rainfall Trends over East Africa. Journal of Climate, 28, 9768-9788. https://doi.org/10.1175/JCLI-D-15-0140.1

Sagero, P. O., Shisanya, C. A., \& Makokha, G. L. (2018). Investigation of Rainfall Variability over Kenya (1950-2012). Journal of Environmental and Agricultural Sciences, 14, $1-15$.

Sen, P. K. (1968). Estimates of the Regression Coefficient Based on Kendall's Tau. Journal of the American Statistical Association, 63, 1379-1389. https://doi.org/10.1080/01621459.1968.10480934

Shisanya, C. A., Recha, C., \& Anyamba, A. (2011). Rainfall Variability and Its Impact on Normalized Difference Vegetation Index in Arid and Semi-Arid Lands of Kenya. International Journal of Geosciences, 2, 36-47. https://doi.org/10.4236/ijg.2011.21004

Taxak, A. K., Murumkar, A. R., \& Arya, D. S. (2014). Long Term Spatial and Temporal Rainfall Trends and Homogeneity Analysis in Wainganga Basin, Central India. Weather and Climate Extremes, 4, 50-61. https://doi.org/10.1016/j.wace.2014.04.005

Terink, W., Hurkmans, R. T. W. L., Torfs, P. J. J. F., \& Uijlenhoet, R. (2010). Evaluation of a Bias Correction Method Applied to Downscaled Precipitation and Temperature Reanalysis Data for the Rhine Basin. Hydrology and Earth System Sciences, 14, 687-703. https://doi.org/10.5194/hess-14-687-2010

Thornton, P. K. et al. (2008). Climate Change and Poverty in Africa: Mapping Hotspots of Vulnerability. African Journal of Agricultural and Resource Economics, 2, 24-44.

Tierney, J. E., Ummenhofer, C. C., \& DeMenocal, P. B. (2015). Past and Future Rainfall in the Horn of Africa. Science Advances, 1, e1500682. https://doi.org/10.1126/sciadv.1500682

Vigna, I., Bigi, V., Pezzoli, A., \& Besana, A. (2020). Comparison and Bias-Correction of Satellite-Derived Precipitation Datasets at Local Level in Northern Kenya. Sustainability, 12, 2896. https://doi.org/10.3390/su12072896

Wetterhall, F., Pappenberger, F., He, Y., Freer, J., \& Cloke, H. L. (2012). Conditioning Model Output Statistics of Regional Climate Model Precipitation on Circulation Patterns. Nonlinear Processes in Geophysics, 19, 623-633.

https://doi.org/10.5194/npg-19-623-2012

Wise, M., Calvin, K., Thomson, A., Clarke, L., Bond-Lamberty, B., Sands, R., Smith, S. J., 
Janetos, A., \& Edmonds, J. (2009). Implications of Limiting $\mathrm{CO}_{2}$ Concentrations for Land Use and Energy. Science, 324, 1183-1186. https://doi.org/10.1126/science.1168475

Worku, G., Teferi, E., Bantider, A., \& Dile, Y. T. (2020). Statistical Bias Correction of Regional Climate Model Simulations for Climate Change Projection in the Jemma SubBasin, Upper Blue Nile Basin of Ethiopia. Theoretical and Applied Climatology, 139, 1569-1588. https://doi.org/10.1007/s00704-019-03053-x

Yang, H., Grassini, P., Cassman, K. G., Aiken, R. M., \& Coyne, P. I. (2017). Improvements to the Hybrid-Maize Model for Simulating Maize Yields in Harsh Rainfed Environments. Field Crops Research, 204, 180-190. https://doi.org/10.1016/j.fcr.2017.01.019

Yang, W., Seager, R., Cane, M. A., \& Lyon, B. (2015). The Rainfall Annual Cycle Bias over East Africa in CMIP5 Coupled Climate Models. Journal of Climate, 28, 9789-9802.

https://doi.org/10.1175//CLI-D-15-0323.1 